\title{
The Study of Destination Risk Management Based on Open Government Data in Taiwan: An Application of Typhoon Warning Report
}

\author{
Ping-Feng Hsia, Ching Li, Cheng-Kuang Fang, Chia-Feng Lin, Hsin-Yen Yen, and Ting-Yen Huang
}

\begin{abstract}
There are many advantages of Open Government Data (OGD), but also some problems on using those data. The purpose of this study is to find out the mainly factor of typhoon which brings impact on northeast tourism destination through analyzing OGD. Typhoon data was collected from warning report, and there were 22 typhoons between 2012-2015. To each typhoon, researchers matched the related typhoon disaster expenditures which were recorded by Northeast and Yilan Coast National Scenic Area Administration. A discriminant analysis was used to discover which characteristics of typhoon caused rehabbing expenditure of tourism destination. The result showed that there were two mainly characteristics of typhoon. One was the path of typhoon, and the other one was the monthly amount of typhoon approaching Taiwan. The average percentage of correction of discriminant function was 90.9\%. According to the result, we suggested the northeast tourism destination manager should pay attention the typhoon path, especially category 2 and 3. Besides, as being hit by several typhoons within a month, tourism destination need to notice the recovery of tourism destination and reinforce the precaution for suffering from second injury.
\end{abstract}

Index Terms-Destination management, discriminant analysis, e-government, open data.

\section{INTRODUCTION}

Due to the proliferation of the Internet and the universal of the cloud storage service, this innovative technique fosters a significant information flow. For the sake of reaching more synergetic development, numerous organizations establish the bridge of open data that makes a large volume of information available to the public [1]. Open data is closely related to people's live. Applying open data is capable for the company to improve its technical, commercial and financial process, and thus increase operational performance [2]. Open data not only plays as an importance role and provide business services, but widely use in each industry. This encourages many countries initially offer open government data (OGD) and represent a shift from a closed to an open system gradually [1]-[3].

Manuscript received December 31, 2016; revised April 5, 2017. This work was supported in part by the Tourism Bureau, Republic of China (Taiwan) Northeast and Yilan Coast National Scenic Area Administration.

Ping-Feng Hsia, Ching Li, Hsin-Yen Yen, and Ting-Yen Huang are with the Graduate Institute of Sport, Leisure and Hospitality Management, National Taiwan Normal University, Taipei, Taiwan (corresponding author: Ting-Yen Huang; e-mail: 60031011a@ntnu.edu.tw, t94002@ntnu.edu.tw, kenjizoro520@gmail.com, timhuang0921@hotmail.com).

Cheng-Kuang Fang and Chia-Feng Lin are with Northeast and Yilan Coast National Scenic Area Administration, Tourism Bureau, Ministry of Transportation and Communication, Taiwan (e-mail: 3g4f@yahoo.com.tw, ea10575@gmail.com).
Governments have conducted many long-term surveys for many years. Because the concept of open data flourishes, those data are accessible to citizens. In other words, setting a OGD makes the system of government become much more open. Governments conducted all kinds of research over the years and accumulate different forms of data. It will carry out economic growth, improvements in democracy and better public services which covers economy, society, tourism and general consumption [2]. For the effective governance, transparency, accountability and citizen participation in democratic processes and policy making, governments begin to undertake the openness of data and establish the mechanism of e-government. Regardless of the great benefits to the society, citizens and business, e-government provides faster request processing, reduction in response times, cost reductions, bridging the digital divide, tailoring services to individuals' needs and the active participation of citizens in the government processes [4].

Furthermore, e-government transfers the administration to public-private partnerships and links government data sharers with user communities. Governments encourage the cooperation such as educational groups to bring plenty of innovations and brisk activities, which differ from conventional governance that facilitate government to provide better services [5].

However, as governments provide OGD or e-government services, it is not adaptable to promote the utility of data and assist affairs. For governments, the cost of releasing data through these OGD portals is less than rendering it into reports or applications. Yet, for data consumers, publishing data online can cause interoperability, scalability, and usability problems [5]. For the partnership of private sector and academia, there are two key challenges. The former may leak valuable information to competitors, and the later may lack motivation to address problems posed by firms [6].

Taiwan Government established "DATA.GOV.TW" in 2013. The data is collected from both central and local government, and the category of data contains most public affairs, including education, finance, economy, meteorology, transportation and any information related to publics. The purpose of building Taiwan OGD are to enhance transparency in governance, increase quality of life, and satisfy the need of industry. There are three steps to implement the Taiwan OGD: (1) data is open to citizens and enterprises; (2) the principle is no charge; (3) data release and exchange based on quantitative, automatic, and systematic. Through publishing OGD, Taiwan Government expect the cooperation between difference ministries and private sectors. It will bring win-win to government, publics, and industries [7]. 
Tourism industry faced the external environment and demonstrated sensitivity to disruptions to the political, economic, military and cultural affairs of nations. As the crisis emerge from the external incident, which would change the destination image and thus effect tourists' buying behavior or travel experience. However, few research were conducted and aimed at the crisis management of destination image [8], [9]. Especially, as the crisis occurs, the private sector merely received the warning from the government and had lack of preparation [8]. In order to minimize the loss caused from the crisis, establishing an advance disaster warning system is the upmost issue to the government. Not only provide the information to publics, also need the support from the private sector and organization. Proactive planning can decrease risks, the waste of time, lacking resource management and lessen the influences caused by disaster and crisis that helps destination image recovery rapidly and independently [10].

Crisis management contains pre-crisis prevention, crisis response and post-crisis [11]. Pre-crisis prevention is considered as the organization of tourism destination actively predict the occurrence of crisis and mentally or physically prepare for precaution. Moreover, to identify upcoming incident and to use warning system to scan and detect the crisis. Besides, to evaluate the seriousness and propose the way to deal with a situation. For the concept of crisis response and post-crisis is the adaptability to the crisis which means to enhance reactivity. Moreover, cumulating the experience from the beginning of crisis till the end of any managed mechanism, which can decrease the negative consequence of crisis.

For the operational management of tourism destination, it is a critical phase that crisis could be detected and analyzed before warning signal. If we ignore this phase, it would bring about enormous damage during next phase and would be difficult to control the loss. It is the reason that the crisis of natural disaster is inevasible. In order to efficaciously manage the crisis immediately, warning system is needed to let the organization of tourism destination face the crisis [9].

Disaster and crisis have various types, includes the management negligence which is internal environment, on the other hand, the politics, economy and natural disaster is regarded as external environment. Among all, natural disaster is often unexpected and incontrollable such as flood, earthquake, typhoon and drought. It is an inevitable and spontaneous incident for tourism destination. With regard to Taiwan, typhoon has caused enormous damage and frequent destruction [9], [11]. However, current prevention of tourism destination which transforms the meteorological information into the scope of disaster is obviously insufficient. It would cause the tourism destination mangers unable to understand the disaster warning, and thus mismanage the precaution [12].

The purpose of this study is to find out the mainly factor of typhoon which brings impact on northeast tourism destination through analyzing OGD. Researchers also try to assist the manager of northeast tourism destination in using OGD to make preparation for natural disaster risk. In this study, researchers used OGD, Typhoon Warning Report, to help manager apply and covert the data into useful information. With the great help, it can improve the analytic ability of typhoon disaster message and inform managers about the scope of disaster. Then, managers can effectively proceed the precaution and preparation.

\section{METHOD}

\section{A. Data Collection}

In this study, we applied the open government data Typhoon Database - established by Central Weather Bureau, Republic of China (Taiwan) in order to assistant tourism destination in conducting risk management of typhoon disaster. From the perspective of risk management, detecting and analyzing warning information is very first step. It can help tourism destination control and prepare for risk effectively. Therefore, the researchers mainly analyzed the first warning report of typhoon issued by Central Weather Bureau. The first issuance was released when there were 24 hours prior to invasion of Taiwan or Kinmen and Matsu within a range of $100 \mathrm{~km}$ by a typhoon that is forecast to be a category 7 in strength, which meant tourism destination had 24 48 hours to plan response measures and estimate loss provision of disaster.

Researchers collected typhoon data with warning report, and there were 22 typhoons from 2012-2015. Based on information of typhoon warning report, researcher matched the related typhoon disaster expenditure recorded by Northeast and Yilan Coast National Scenic Area Administration.

\section{B. Typhoon Database (Central Weather Bureau)}

Typhoon Database is released online and managed by Central Weather Bureau, Republic of China (Taiwan). Users can do basic search, advance search, and outlier search in the database. The basic research includes searching by category, viewing historical typhoon list, browsing typhoon list with warning report, and searching by distance. The advance search contains searching by users' definition, rainfall statistics, and wind speed statistics. In advance research, users can check typhoon information base on several criteria, including with or without warning report, latitude/longitude, and year. The outlier research supplies Weather Stations rainfall statistics, outlier basic information, and outlier searching by Weather Station. The outlier record contains rainfall, wind speed, central pressure of typhoon, and storm radius (Fig. 1). However, Typhoon Database is an interactive website. It does not provide users any file to download. [13]。

Researchers used typhoon warning report which could be found in typhoon list with warning report of basic search. Central Weather Bureau issues two different kind of warning report, including sea warning report and land warning report. During typhoon warning period, the interval of issuance is 3 hours, with shorter intervals if necessary. The first warning report is released when there were 24 hours prior to invasion of Taiwan or Kinmen and Matsu within a range of $100 \mathrm{~km}$ by a typhoon that is forecast to be a category 7 in strength. Therefore, managers of tourism destination have at least 24 hours to make preparation.

We extracted information from typhoon warning report described as follow (Fig. 2) [13]. 


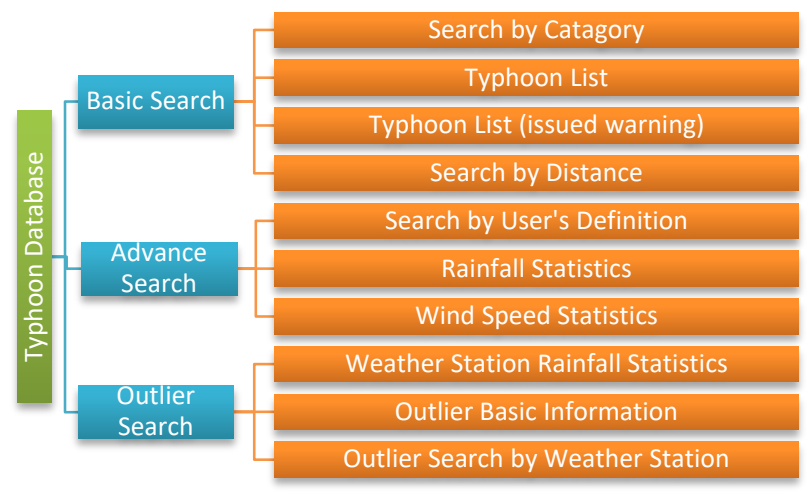

Fig. 1. The structure of typhoon database.

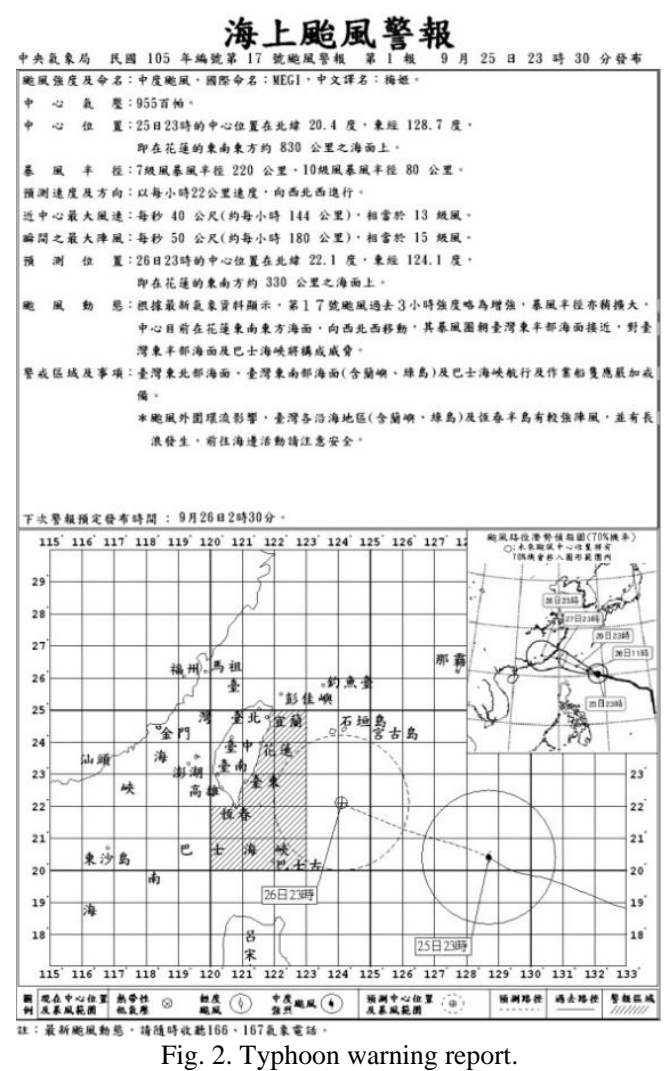

1) Issuing time and date: the issuing time and date of current typhoon warning report. The study only extracted and coded issuing date of typhoon.

2) Typhoon intensity and name: the intensity and international name. The studied re-coded intensity as ordinal variable.

3) Storm radius: The distance from the typhoon center to where the average wind speed drops to $14 \mathrm{~m} / \mathrm{s}$ (for wind of category 7) and $25 \mathrm{~m} / \mathrm{s}$ (for wind of category 10).

4) Forecast speed and direction: expressed in kilometers per hour and 16-point directions.

5) Near-center maximum wind speed: Average wind speed taken for 10 minutes, expressed in meters per second (kilometers per hour).

6) Instantaneous maximum gust speed: instantaneous peak wind speed, expressed in meters per second (kilometers per hour).

7) Map for forecast of typhoon's potential path: see Fig. 3 for reference. The study weighted each path according to the distance with Northeast tourism destination area.

8) Others: The study coded monthly amount of typhoon and monthly amount of typhoon approaching Taiwan according to the information of warning report.

\section{Procedure of Coding}

Typhoon Database does not provide files for users to download. Therefore, researchers have to build a file and code the data first before analyze.

Issuing date, typhoon name, storm radius, forecast speed, near-center maximum wind speed, and instantaneous maximum gust speed are coding as original data. Typhoon intensity, forecast speed and direction change, and paths of typhoons have to be re-coding. Besides, the study also codes monthly amount of typhoon and monthly amount of typhoon approaching Taiwan according to the information of warning report. The procedures of coding are described as follow.

1) Typhoon intensity: Typhoon warning report defines typhoon intensity as intense, moderate, and minor. The study re-cords typhoon intensity as number 3 to 1 , which means weight intense typhoon as 3 , moderate typhoon as 2 , and minor typhoon as 1 .

2) Forecast speed and direction change: there are two situations about forecast speed and direction change in Typhoon Warning Report. One is no extra description of forecast speed and direction change, then the study codes it as no change. The other situation is there is extra description of forecast speed and direction change, then the study codes it bases on the descriptive value.

3) Paths of typhoon: Central Weather Bureau distinguishes paths of typhoon as several categories[14] (Fig. 3). Typhoon Warning report disclosures typhoon potential path. The study weight path of typhoon according to the distance between path and Northeast tourism destination which reflects the level of influence from typhoon. Path category two and six are coded as 4, category one and three as 3, category seven and nine as 2 , and others includes category four, five, eight are coded as 1 .

\section{Data Analysis}

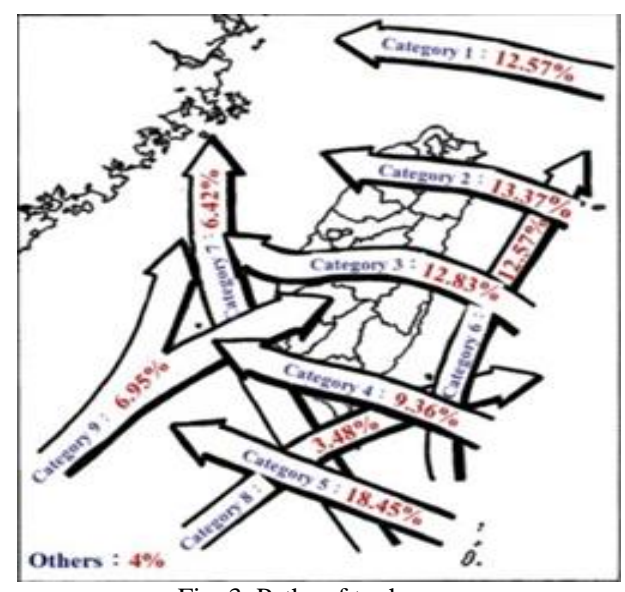

Fig. 3. Paths of typhoons.

The discriminant analysis was used to describe the different typhoon characteristic variable that was considered to have impact on tourism destination. On the one hand, esearchers extract typhoon characteristic variables, including typhoon intense, storm radius, forecast speed, near-center maximum wind speed, instantaneous maximum gust speed, typhoon potential path, monthly amount of typhoon, and monthly amount of typhoon approaching Taiwan. 
On the other hand, Northeast and Yilan Coast National Scenic Area Administration provides expenditure of typhoon disaster of facility repairmen from 2012 to 2015. Rsearchers reorganizes the materials to match the related typhoon. Firstly, researcher organized the expenditure by month and match the date with related typhoon. Then we defined expenditures as two group - disaster expenditure occurring and no disaster expenditure.

\section{Result}

There were 22 valid datasets in this study, and the percentage of validation was 100 percent. The discriminant analysis showed there was a significant canonical discriminant function. The eigenvalue of function one was 1.16 , and the canonical correlation of function one was .73 . The variability explained by the function one is 100 percent. the summary of canonical discriminant analysis showed function one had discrimination and explanation (Table 1).

The magnitudes of standardized coefficients indicated how strongly the discriminating variables effect the score. The function one showed the standardized coefficient of weight of path was .79 and the standardized coefficient of amount of typhoon approaching was .63 (Table I).

Unstandardized coefficients were the mean of the discriminant function one scored by group for each function calculated. We could find that the weight of path group had a mean of 0.92 and the amount of typhoon approaching had a mean of 1.25 (Table I).

According to summary of canonical discriminant function, the path of typhoon and how many typhoon approaching Taiwan were two mainly factors to cause expenditures of Northeast tourism destination, especially path of typhoon.

Bringing typhoon characteristic variable into the discriminant function one could calculate the score of each case, and predict which expenditure category should each case belong. According to classification result, the percentage of observations that were predicted correctly in the no expenditure group was $81.8 \%$, and were predicted correctly in the with expenditure group was $100 \%$. The average percentage of correction of discriminant function one was $90.9 \%$ (Table II).
TABLE I: SUMMARY OF CANONICAL DISCRIMINANT FUNCTIONS

\begin{tabular}{|c|c|c|}
\hline \multirow[b]{2}{*}{ Variables } & \multicolumn{2}{|c|}{ Function One } \\
\hline & $\begin{array}{l}\text { Standardized } \\
\text { Coefficient }\end{array}$ & $\begin{array}{l}\text { Unstandardized } \\
\text { coefficients }\end{array}$ \\
\hline Weight of Path & .79 & .92 \\
\hline $\begin{array}{l}\text { Amount of Typhoon } \\
\text { approaching }\end{array}$ & .63 & 1.25 \\
\hline (constant) & & -3.45 \\
\hline Canonical Correlation & \multicolumn{2}{|c|}{.73} \\
\hline Eigenvalues & \multicolumn{2}{|c|}{1.16} \\
\hline$\%$ of Variance & \multicolumn{2}{|c|}{$100 \%$} \\
\hline
\end{tabular}

TABLE II: CLASSIFICATION RESULTS

\begin{tabular}{llccc}
\hline \hline & & \multicolumn{3}{c}{ Predicted group } \\
\cline { 3 - 4 } Original group & \multicolumn{2}{c}{ T } & \multirow{2}{*}{ Total } \\
\cline { 3 - 4 } & & No expenditure & With expenditure & \\
\hline \multirow{2}{*}{1} & No & 9 & 2 & 11 \\
& expenditure & $(81.8 \%)$ & $(18.2 \%)$ & $(100 \%)$ \\
\multirow{2}{*}{2} & With & & 11 & 11 \\
& expenditure & & $(100 \%)$ & $(100 \%)$ \\
\hline \hline
\end{tabular}

Standardized coefficients could be used to calculate the discriminant score for a given case. The score was calculated in the same manner as a predicted value from a linear regression, using the standardized coefficients and the standardized variables. In this study, the function scores would be calculated using the following equations:

$P=0.92 *$ Weight of Path

$+1.25 *$ Amount of Typhoon Approaching - 3.45

$P<0.01$ predict as No expenditure

$P>=0.01$ predict as With expenditure

The study used Typhoon data and expenditure data in 2016 to test the discriminant function. There were 5 cases before the end of October, 2016 (Table III). After bringing the weight of path and the amount of typhoon approaching data into the function, the score of each case was calculated. If the score was equal or more than 0.01 , the case was predicted as the with expenditure group, which meant the related typhoon would cause expenditure. Otherwise, the score was less than 0.01 , the case was predicted as the no expenditure group, which meant the related typhoon would not cause expenditure.

TABLE III: SUMmaRY OF PREDICTEd ClassifiCATION OF TYPHOON DisASTER EXPENDITURE IN 2016

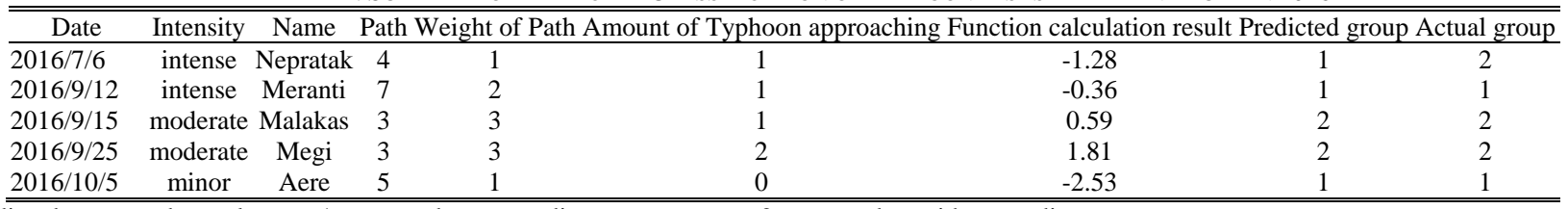

*predicted group and actual group 1 presented no expenditure group; group 2 presented as with expenditure group

Take Aere Typhoon as an example, the value of weight of path was 1, and the value of amount of typhoon approaching was 0 . Brought those values into the function, the sore was -2.53 which was less than 0.01 . Therefore, Aere Typhoon was predicted as no expenditure group (Table III).

The result of 2016 testing data in Table III illustrated only Nepratak Typhoon was mispredicted as no expenditure group. The percentage of testing data that were predicted correctly in the no expenditure group was $100 \%$, and were predicted correctly in the with expenditure group was $66.6 \%$. The average percentage of correction of discriminant function one was $80 \%$ (Table III).

\section{CONCLUSION}

\section{A. Discussion and Implications}

The research applied the open data titled "Typhoon database" which is retrieved from Taiwan Central Weather Bureau. The data was transformed and analyzed to assist managers of tourism destination in investigation before 
typhoon disaster. Moreover, we could effectively determine which features of typhoon would lead to recovery loss. It allows the manager mapping out the preparation for typhoon disaster in advance.

The result found out that "the path of typhoon" and "the amount of typhoon within a month" are main factors. That is, if the path of typhoon is forecasted as category 2 and 3 from typhoon warning report, it is necessary to alert for precaution and prevention. Also, as being hit by several typhoons within a month, we need to notice the recovery of tourism destination and reinforce the precaution for suffering from second injury.

Furthermore, the data of 2016 was verified on the functions resulted from discrimination analysis. The research found out that the functions have the accuracy rate of $80 \%$ through verified examination. Due to the limits of data collection, tourism destination simply provided the data from 2012 to 2015 . We suggest managers to strengthen the internal administrative data and proceed long-term collection, which can be incessant to revise and verify the predictive formula.

\section{B. Limitation and Recommendations}

As far as the user to the open database, the usability and handleability of data are extremely critical factors. As conducting the research, we discovered that open data-"typhoon database"-announced by Taiwan Tourism Bureau was designed as point-and-click website. Even though the pages are customized and interactive, most of the data do not provide files for download, which composes the problem of usability. Moreover, typhoon warning report is given in pdf format. The data needs to be coded before analyzing which composes the problem of handleability. Hence, the research suggests that typhoon database does not only provide web searching but for data download at one time, such as CSV and XML. Likewise, digitizing the data on typhoon warning report allows data field can be used directly, such as create typhoon warning report by XML.

Past studies also shows that in spite of open government database has been established, OGD cannot be effectively used by other organization units. Educational groups also lack the motivation of solving organization problem. The research was commissioned by Northeast and Yilan Coast National Scenic Area Administration for connecting and analyzing typhoon database. We thus discovered that governmental organizations are deficient in the specialty of interpreting data. Therefore, educational groups are encouraged to conduct the research with governments as open data publishes. Thereby, the value of data is magnified which surely stimulates the generation of creative activity.

\section{REFERENCES}

[1] L. F. R. Simón, R. A. Avilés, I. Botezan, F. V. Gastaminza, and S. C. Serrano, "Open data as universal service. New perspectives in the information profession," Procedia - Soc. Behav. Sci., vol. 147, pp. 126-132, 2014.

[2] T. Davies, F. Perini, and J. Alonso, "Researching the emerging impacts of open data ODDC conceptual framework," J. Community Informatics, vol. 12, no. 2, pp. 148-178, 2013.

[3] M. Janssen, Y. Charalabidis, and A. Zuiderwijk, "Benefits, adoption barriers and myths of open data and open government," Inf. Syst. Manag., vol. 29, no. 4, pp. 258-268, 2012.

[4] N. Veljković, S. Bogdanović-Dinić, and L. Stoimenov, "Benchmarking open government: An open data perspective," Gov. Inf. Q., vol. 31, no. 2, pp. 278-290, 2014.
[5] J. Hendler, J. Holm, C. Musialek, and G. Thomas, "US government linked open data: Semantic.data.gov," IEEE Intell. Syst., vol. 27, no. 3, pp. 25-31, 2012.

[6] M. Perkmann and H. Schildt, "Open data partnerships between firms and universities: The role of boundary organizations," Res. Policy, vol. 44, no. 5, pp. 1133-1143, 2015.

[7] National Development Concil. (2016). Data.Gov.TW. [Online]. Available: http://data.gov.tw/

[8] B. Prideaux, "The need to use disaster planning frameworks to respond to major tourism disasters: Analysis of Australia's response to tourism disasters in 2001," Safety and Security in Tourism: Relationships, Management, and Marketing, 2012, pp. 281-298.

[9] G. Santana, "Crisis management and tourism," J. Travel Tour. Mark., vol. 15 , no. 4, pp. 299-321, 2004.

[10] B. W. Ritchie, H. Dorrell, D. Miller, and G. A. Miller, "Crisis communication and recovery for the tourism industry," J. Travel Tour. Mark., vol. 15, no. 2-3, pp. 199-216, 2004.

[11] D. Glaesser, Crisis Management in the Tourism Industry, 2006.

[12] The United Nations Office for Disaster Risk Reduction. (2015). Disasters in numbers. [Online]. Available: https://www.unisdr.org/we/inform/publications/47804

[13] Central Weather Bureau. (2016). Typhoon database. [Online]. Available: http://rdc28.cwb.gov.tw/

[14] Central Weather Bureau. (2016). Categorized paths of typhoons invading Taiwan. [Online]. Available: http://www.cwb.gov.tw/V7e/knowledge/encyclopedia/ty017.htm

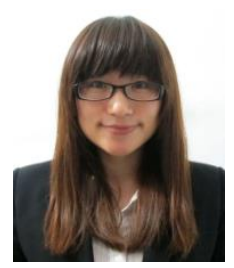

Ping-Feng Hsia is a $\mathrm{PhD}$ student and has a master of education degree in Graduate Institute of Sport, Leisure and Hospitality Management, National Taiwan Normal University. She also received the bachelor of administration degree in the Department of Sport and Leisure Management, National Taipei University. Her research interests are tourist behavior, tourism destination management, and data analysis.

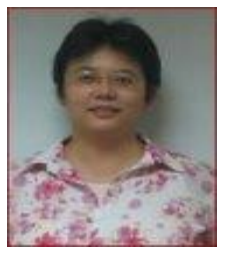

Ching $\mathbf{L i}$ is a professor of Graduate Institute of Sport, Leisure and Hospitality Management, National Taiwan Normal University, Taiwan. She had a $\mathrm{PhD}$ degree in environmental science, State University of New York, NY, USA. Her research expertise focuses on recreational resource management, environmental planning and assessment, and leisure behavior.

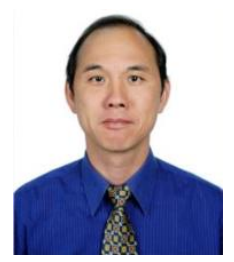

Cheng-Kuang Fang is a director in Northeast and Yilan Coast National Scenic Area Administration, Tourism Bureau, Ministry of Transportation and Communication.

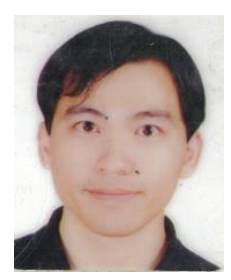

Chia-Feng Lin is a Senior Engineer in Northeast and Yilan Coast National Scenic Area Administration, Tourism Bureau, Ministry of Transportation and Communication.

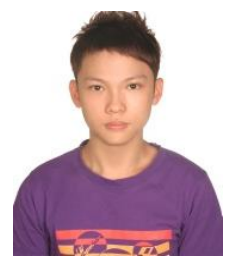

Hsin-Yen Yen is a $\mathrm{PhD}$ student and has a master of education degree in Graduate Institute of Sport, Leisure and Hospitality Management, National Taiwan Normal University. He also received bachelor degree in Science of Nursing, Taipei Medical University, Taiwan. His research interests are physical activity, sport therapy, health promotion, wellness tourism, and data analysis.

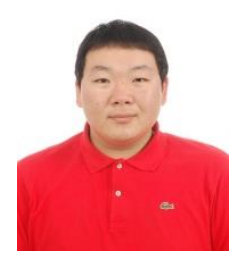

Ting-Yen Huang works as research assistant commissioned by Taiwan's Tourism Bureau. He was a Master's degree student in Graduate Institute of Sport, Leisure and Hospitality Management, National Taiwan Normal University. He also received bachelor degree in Department of Food Science, National Taiwan Ocean University. His research interests are human resource management. 